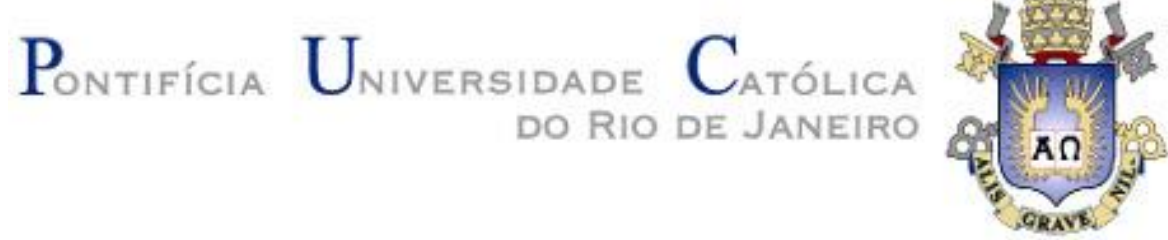

Mariana Lopes da Silva Pereira

\title{
Experiências turísticas memoráveis e
}

nostalgia

Dissertação de Mestrado

Dissertação apresentada ao Programa de Pós-Graduação em Administração de Empresas da PUC-Rio como requisito parcial para obtenção do grau de Mestre em Administração de Empresas.

Orientador: Prof. Luis Fernando Hor-Meyll Alvares

Rio de Janeiro

Abril de 2017 


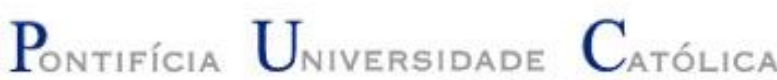

Mariana Lopes da Silva Pereira

\section{Experiências turísticas memoráveis e nostalgia}

Dissertação apresentada como requisito parcial para obtenção do grau de Mestre pelo Programa de PósGraduação em Administração de Empresas do Departamento de Administração da PUC-Rio. Aprovada pela Comissão Examinadora abaixo assinada.

Prof. Luis Fernando Hor-Meyll Alvares Orientador

Departamento de Administração - PUC-Rio

Profa. Angela Maria Cavalcanti da Rocha

Departamento de Administração - PUC-Rio

Profa. Denise Franca Barros Universidade do Grande Rio

Profa . Mônica Herz

Vice-Decana de Pós-Graduação do CCS - PUC-Rio 
Todos os direitos reservados. É proibida a reprodução total ou parcial do trabalho sem autorização da universidade, da autora e do orientador.

\section{Mariana Lopes da Silva Pereira}

Graduou-se em Administração de Empresas com ênfase em Marketing na Pontifícia Universidade Católica do Rio Janeiro (PUC-Rio) em 2010. Concluiu MBA Em Gestão Empresarial na Fundação Getúlio Vargas (FGV-RJ) em 2015. Possui grande experiência em compras e relacionamento com fornecedores no varejo físico e de aeroportos, tendo participado de processos de negociação com marcas locais e globais.

Ficha Catalográfica

Pereira, Mariana Lopes da Silva

Experiências turísticas memoráveis e nostalgia / Mariana Lopes da Silva Pereira ; orientador: Luis Fernando Hor-Meyll Alvares. 2017.

50 f. : il. color. ; $30 \mathrm{~cm}$

Dissertação (mestrado)-Pontifícia Universidade Católica do Rio de Janeiro, Departamento de Administração, 2017.

Inclui bibliografia

1. Administração - Teses. 2. Turismo. 3. Experiências memoráveis. 4. Nostalgia. 5. Comportamento do consumidor. I. Alvares, Luis Fernando Hor-Meyll. II. Pontifícia Universidade Católica do Rio de Janeiro. Departamento de Administração. III. Título.

CDD: 658 


\section{Agradecimentos}

Agradeço à minha família, pelo apoio e paciência ao longo de todas as etapas do ङ Mestrado;

Ao meu namorado, Igor, pelo incentivo durante o curso e palavras confortantes nos momentos mais difíceis;

A meus amigos e colegas da PUC-Rio, pelas conversas e interesse demonstrado pelo tema e ao longo do desenvolvimento deste estudo;

Ao meu orientador, Luis Hor-Meyll, pela atenção e ajuda na elaboração do estudo. 


\section{Resumo}

Pereira, Mariana Lopes da Silva; Hor-Meyll, Luiz Fernando. Experiências turísticas memoráveis e nostalgia. Rio de Janeiro, 2017. 50 p. Dissertação de Mestrado - Departamento de Administração, Pontifícia Universidade Católica do Rio de Janeiro.

O turismo pode reviver experiências e momentos que ficaram no passado. Este estudo identifica dimensões por meio das quais experiências memoráveis provocam nostalgia em relação a locais de turismo. Foram conduzidas quinze entrevistas em profundidade, analisadas com base em métodos da filosofia fenomenológica. Experiências memoráveis que remetem a sentimentos nostálgicos não parecem ser necessariamente relacionadas aos locais ou destinos, mas à reprodução de sensações e emoções ali vivenciadas, ou à lembrança de momentos passados com familiares, amigos próximos ou parceiros românticos.

\section{Palavras-chave}

Turismo; experiências memoráveis; nostalgia; comportamento do consumidor. 


\section{Abstract}

Pereira, Mariana Lopes da Silva; Hor-Meyll, Luiz Fernando (Advisor). Memorable tourism experiences and nostalgia. Rio de Janeiro, 2017. 50 p. Dissertação de Mestrado - Departamento de Administração, Pontifícia Universidade Católica do Rio de Janeiro.

Tourism may relive experiences and moments from the past. This study identifies dimensions from memorable tourism experiences which can lead to nostalgia related to tourism locations. We proceeded fifteen interviews that were analyzed based on phenomelogical method. The main findings show that memorable experiences which create nostalgic feelings don't seem to be necessarily related to locations or touristic destinations, but to sensations and emotions lived there, or moments experienced with family, with closer friends or in romantic relationships.

\section{Keywords}

Tourism; memorable experiences; nostalgia; consumer behavior. 


\section{Sumário}

1 Introdução

1.1. Contexto e Tema do Estudo ..................................................... 9

1.2. Relevância do Estudo ...................................................................... 12

1.3. Delimitações do Estudo

2 Revisão de Literatura

2.1. Experiências no Consumo

2.1.1. Experiências Turísticas Memoráveis …………........................... 15

2.2. Nostalgia $\ldots$

3 Método

3.1. Seleção dos Entrevistados ……………………………................. 24

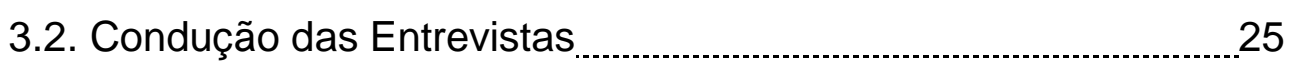

3.3. Explicitação dos Dados

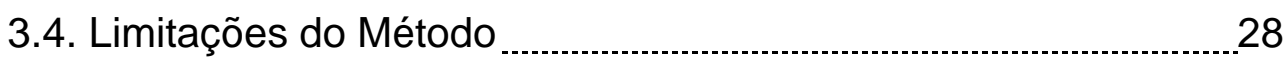

4 Resultados $\ldots$

4.1. Momentos de interação com amigos, familiares ou parceiros românticos

4.2. Expectativa em relação ao local de turismo ................................... 35

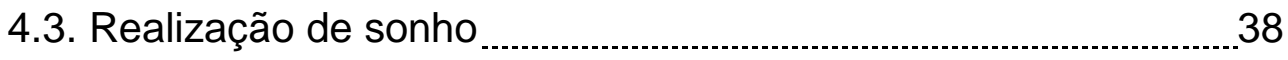

5 Conclusões

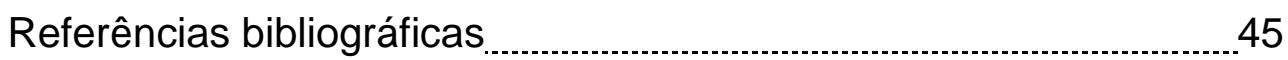




\section{Lista de Tabelas}

Tabela 1 - Lista de Entrevistados

25

\section{Lista de Figuras}

Figura 1 - Dimensões identificadas nos dados 28

Figura 2 - Necessidade de comunicação e informação no consumo de turismo 38 


\section{Introdução}

\section{1.}

\section{Contexto e Tema do Estudo}

Nas últimas décadas, o turismo vem crescendo e tornando-se setor da economia com grande relevância no desenvolvimento socioeconômico em todo o mundo. Os negócios relacionados à indústria têm passado por transformações que contribuem para a geração de benefícios para destinos e atividades turísticas, inclusive aumentando a diversificação e a concorrências entre destinos (WORLD TOURISM ORGANIZATION, 2016).

O estudo "Viagens e Turismo: Impacto Econômico", do Conselho Mundial de Viagens e Turismo (WTTC) de 2014, revelou que o Brasil ocupa o sexto lugar no ranking de países. São considerados indicadores do setor, como sua participação no PIB, a capacidade de gerar empregos e investimentos públicos e privados realizados. No relatório, há projeção de que o setor representará $10,3 \%$ do PIB em 2024, equivalente a $\mathrm{R} \$ 700$ bilhões - um crescimento significativo se comparado aos R $\$ 492$ bilhões movimentados entre atividades diretas, indiretas e induzidas pela indústria em 2014. O estudo também mostra que o setor movimentou US\$ 7,6 trilhões no mundo no mesmo ano, representando $10 \%$ de toda a riqueza do período (ASSOCIAÇÃO BRASILEIRA DE EMPRESAS DE EVENTOS, 2014).

Para a Organização Mundial do Turismo, turistas são os viajantes que ficam fora de seus domicílios por período que não ultrapassa um ano (IPEA, 2010). Segundo relatório da Pesquisa e Planejamento Econômico (PPE) do Instituto de Pesquisa Econômica Aplicada (IPEA), há definições que consideram que o turista é quem fica por mais de vinte e quatro horas no destino de visita (IPEA, 2010). Considera-se neste trabalho que turismo é a atividade que promove gastos de consumidores que estão fora de seu domicílio por período entre um dia e um ano.

Esses viajantes consomem em diferentes setores, como alimentação, transporte, hospedagem e lazer (IPEA, 2010). Buhalis (2000) aponta que muitos 
destinos são compostos e percebidos por meio de seis componentes: atrações, acessibilidade, amenidades (acomodação, alimentação, comércio), pacotes disponíveis, atividades e serviços auxiliares (bancos, telecomunicações, hospitais, entre outros). Adotou-se aqui, como locais de turismo, aqueles que têm relação com tais áreas e componentes - como restaurantes, bares e lanchonetes; meios de transporte e rotas; hotéis, pousadas, albergues e casas utilizadas como hospedagem; shows, eventos, festivais, atrações (naturais, artificiais, patrimônios culturais) e pontos turísticos; comércio e atividades desempenhadas durante a viagem.

Para melhor entender o comportamento do consumidor em local de turismo, é válido ir além da análise dos motivos e das situações em que ocorrem as transações de compra e as experiências. É também relevante estudar pensamentos, sentimentos e reações, assim como influências exercidas sobre ele e que o levam a consumir.

Levando em consideração que turistas são contadores de histórias, narram fatos vividos em viagens, assim como suas reações e sentimentos nelas despertados, a experiência por eles vivida gera memórias e impressões sobre locais e sobre produtos e serviços consumidos no destino turístico (GRETZEL ET AL, 2006; PACE, 2008).

Também, considerando que o turismo é um tipo de consumo que busca experiências prazerosas, positivas e extraordinárias em comparação com seu dia a dia (BOSANGIT ET AL, 2015; LO; MCKERCHER, 2015), ele é enquadrado como um consumo hedônico, no qual as pessoas buscam uma vida mais prazerosa e com experiências significativas (AHUVIA, 2005; HOLBROOK; HIRCHMANN, 1982; KIM ET AL, 2012; RUSSEL, 2008). Uma experiência de consumo tem a capacidade de atender uma busca por viver ou reviver bons momentos (HAVLENA; HOLAK, 1991; HOLBROOK, 1993), permitindo que turistas relembrem períodos marcantes vividos anteriormente.

Aumentar as chances de que indivíduos tenham experiências memoráveis em local turístico, definidas como experiências de turismo positivas recordadas posteriormente à sua vivência (KIM ET AL, 2012), é relevante para aumentar competitividade do local, ao elevar a intenção de revisita e de recomendação (SRINIVASAN; SRIVASTANA, 2010; WOODSIDE ET AL, 2004). 
É válido ressaltar que movimentos que inspiram o consumo não são influenciados por circunstâncias somente do presente, mas também por fatores do passado (BAMBAUER-SACHSE; GIERL, 2009; CHEN ET AL, 2014; HOLBROOK, 1993; HOLBROOK; SCHINDLER, 1991; YOON; YYSAL, 2005). Experiências vividas em período anterior, e armazenadas na memória de um consumidor ou de seus grupos, são capazes de gerar sentimento de nostalgia (HOOLBROK, 1993; HOLAK ET AL, 2006) que, por sua vez, têm forte efeito na estrutura de preferências (HOLBROOK, 1993) e podem estimular decisões e comportamento (BAMBAUER-SACHSE; GIERL, 2009; CHEN ET AL, 2014; HOLBROOK, 1993; HOLBROOK; SCHINDLER, 1991; LASALETA ET AL, 2014; YOON; YYSAL, 2005; ZHOU ET AL, 2012). Dentre ofertas, escolhas são feitas não somente por sua função ou utilidade, mas também, pelo seu significado (BELK, 1988; HIRSCHMAN; HOLBROOK, 1982) e associadas a sentimentos de desejo ou de prazer (HIRSCHMAN; HOLBROOK, 1982; HOLBROOK; HIRSCHMAN, 1982).

Em estudos anteriores, a nostalgia pode ser observada como um recurso psicológico que contribui para desenvolver e sustentar um significado para as vidas do consumidor (ROUTLEDGE ET AL, 2011). Também, foi identificada a correlação positiva entre nostalgia e experiências memoráveis em turismo (GORDON, 2013; LEE, 2015), indicando que o sentimento nostálgico tem efeito mediador sobre emoções pessoais e experiências positivas marcantes (LEE, 2015). Desse modo, entendendo que o consumo de experiências tem maior possibilidade de gerar respostas emocionais (HIRSCHMAN; HOLBROOK, 1982; HOLBROOK; HIRSCHMAN, 1982) e que as pessoas costumam lembrar de emoções em experiências de viagens no seu processo de decisão de consumo (KIM ET AL, 2012), o objetivo deste trabalho é identificar dimensões por meio das quais são manifestadas experiências memoráveis que provocam nostalgia em relação a locais de turismo. 


\section{2 . \\ Relevância do Estudo}

Pesquisas identificaram que a nostalgia interfere nas preferências e decisões de consumo (BAMBAUER-SACHSE; GIERL, 2009; CHEN ET AL, 2014; HOLBROOK, 1993; HOLBROOK; SCHINDLER, 1991; LASALETA ET AL, 2014; YOON; YYSAL, 2005; ZHOU ET AL, 2012) e que há correlação entre nostalgia e experiências memoráveis em turismo (GORDON, 2013; LEE, 2015), reforçando que o sentimento nostálgico influencia na criação de experiências positivas marcantes (LEE, 2015). Embora alguns estudos tenham levantado antecedentes de uma experiência memorável no contexto do turismo (CHANDRALAL; VALENZUELA, 2013; GORDON, 2013; KIM, 2014; LEE, 2015; TUNG; RITCHIE, 2011), não foi identificado na literatura estudo sobre quais experiências memoráveis desencadeiam nostalgia. A importância deste estudo reside na identificação de categorias de experiências memoráveis que provocam nostalgia em relação a locais de turismo.

Com previsão de crescimento em estudos da área (ASSOCIAÇÃO BRASILEIRA DE EMPRESAS DE EVENTOS, 2014; IPEA, 2010), apontando para o setor como promissor, este estudo faz-se relevante por acrescentar conhecimentos sobre como se comportam consumidores de turismo, contribuindo para que empresários do ramo tenham informações para alinharem decisões e estratégias em busca de otimizar ganhos e melhor atender aos turistas. Segundo apontado por Lehto, O'Leary e Morrison (2004), a literatura existente sustenta que consumidores buscam reduzir riscos em suas decisões e experiências anteriores afetam escolhas futuras de compra. Logo, estudiosos e profissionais de marketing podem usar certos valores, simbolismos e estratégias para atrair consumidores, estimulando a criação de experiências memoráveis positivas que provoquem sentimentos de nostalgia e, como consequência, promovam consumo (CUI, 2015). O conhecimento aqui resultante poderá ser interessante para os empresários do setor de turismo, ao permitir que façam ajustes em decisões, aumentando e influenciando positivamente o comportamento do consumidor, maximizando a satisfação, atraindo novas visitas dos turistas, garantindo lucros e, também, prosperidade para as atividades ligadas ao setor. 


\section{3. \\ Delimitações do Estudo}

Por meio de relatos e de memórias autobiográficas, este estudo aborda experiências relacionadas a vivências individuais em viagens de turismo, que promovem gastos de consumidores que estão fora de seu domicílio por período entre um dia e um ano. Não foram incluídas no estudo viagens estritamente ligadas a trabalho.

Foram estudadas experiências memoráveis que provocam nostalgia pessoal, relacionadas diretamente a experiências pessoais e memórias individuais (HOLAK ET AL, 2006), em relação a locais de turismo, compreendidos como restaurantes, bares e lanchonetes; meios de transporte e rotas; hotéis, pousadas, albergues e casas utilizadas como hospedagem; shows, eventos, festivais, atrações e pontos turísticos; comércio e atividades desempenhadas durante a viagem. Assim, não estão no escopo deste estudo experiências memoráveis que não provocam nostalgia. 


\section{2 \\ Revisão de Literatura}

Com a intenção de contextualizar o problema de pesquisa, este capítulo apresenta conceitos e estudos relacionados aos grandes temas envolvidos: experiências no consumo, experiências turísticas memoráveis e nostalgia.

\section{1. \\ Experiências no Consumo}

O termo experiência pode ser definido, de modo geral, como "sensação ou aquisição de conhecimento resultante da participação de uma pessoa in atividades diárias" (GUPTA; VAJIC, 1999, p.35). Na compreensão de marketing, experiência está atrelada a atividades promovidas por um prestador de serviço dentro do contexto social (GUPTA; VAJIC, 1999; PINE; GILMORE, 1998).

No processo de decisão de consumo, após a identificação de algum "problema" por parte do consumidor, provocado por estímulos externos e/ou sensações internas, é gerada uma necessidade, surgindo um impulso para atendêla, uma motivação para satisfazê-la (CHARTRAND ET AL, 2008). A necessidade pode ser por um produto ou um serviço, mas também por interação social, divertimento e prazer (ARNOLD; REYNOLDS, 2003). Além da aquisição tradicional de bens materiais e do consumo de serviços prestados, há também a busca do consumidor por experiências, por vivências sobre as quais tem intenção de satisfazer desejos, não somente atender a funções utilitárias (HIRSCHMAN; HOLBROOK, 1982).

Compreender o consumo pela perspectiva da experiência é explorar o ofertado e seus "significados simbólicos de características mais subjetivas" (HIRSCHMAN; HOLBROOK, 1982, p.134), como autoimagem, emoções, valores, desejos de consumo (SRINIVASAN; SRIVASTANA, 2010).

Entendendo que "bens são tangíveis, serviços são intangíveis e experiências são memoráveis" (PINE; GILMORE, 1998, p.98), o tipo de resposta buscada ao 
consumo de experiências é diferente - as reações obtidas são respostas hedônicas (HIRSCHMAN; HOLBROOK, 1982), como a realização, o escapismo, a espontaneidade e o entusiasmo (BABIN ET AL, 1994). Para Hirschman e Holbrook (1982), o consumo hedônico é bastante ligado ao sistema afetivo e emocional, estando relacionado a fantasias (sonhos, desejos), sentimentos (emoções) e divertimento/prazer.

A experiência é uma atividade que exige do indivíduo participação, interação e promove uma transformação durante o consumo (PINE; GILMORE, 1998). Dois tipos de experiências foram apontados por Bhattacharjee e Mogilner (2014): ordinária e extraordinária. As ordinárias são situações comuns, frequentes e vividas no cotidiano. Por outro lado, as extraordinárias fogem do dia-a-dia, são incomuns, atípicas (BHATTACHARJEE; MOGILNER, 2014) e, por isso, mais facilmente lembradas e com potencial para tornarem-se especiais (BHATTACHARJEE; MOGILNER, 2014; GRETZEL ET AL, 2006; KIM ET AL, 2012).

Um momento ou evento memorável pode ser considerado como uma experiência inesquecível e extraordinária (CARÙ; COVA, 2003). Assim, no contexto de consumo, para que atuem com maior probabilidade de gerarem repetição de consumo e a lealdade do consumidor (SRINIVASAN; SRIVASTANA, 2010), as empresas devem focar em promover "engajamento individual dos consumidores, ao criarem um evento memorável" (PINE; GILMORE, 1998, p.98), transformando algo comum em positivamente marcante (PINE; GILMORE, 1998).

Como o turismo pode ser considerado um consumo hedônico (AHUVIA, 2005; HOLBROOK; HIRCHMANN, 1982; KIM ET AL, 2012; RUSSEL, 2008) e as experiências geram memórias e impressões sobre locais e produtos e serviços consumidos em destino turístico (GRETZEL ET AL, 2006), estudos sobre experiências memoráveis no setor são melhor apresentados aqui.

\subsection{1.}

\section{Experiências Turísticas Memoráveis}

Experiência no turismo é considerada como a "avaliação subjetiva de um indivíduo (afetiva, cognitiva e comportamental) sobre eventos relacionados a 
atividades turísticas, que começa antes (planejamento e preparação), durante (no destino) e depois da viagem (recordação)" (TUNG; RITCHIE, 2011, p.1369).

Turistas costumam compartilhar suas experiências e memórias de locais de turismo (GRETZEL ET AL, 2006; PACE, 2008), apresentando a outras pessoas, por meio de narrativas, suas impressões, ajudando na formação da identidade de quem conta e na disseminação de informação (BOSANGIT ET AL, 2015). A própria narrativa é uma atividade que consolida o vivido na memória do viajante (TUNG; RITCHIE, 2011), assim como participa do processo de atribuição de significado às experiências de viagem (GRETZEL ET AL, 2006) e auxilia no seu resgate na memória (TUNG; RITCHIE, 2011).

Alguns elementos sensoriais, percebidos pelos cinco sentidos - visão, audição, tato, paladar e olfato - podem influenciar na criação de memórias, inclusive estimulando a lembrança, o desenvolvimento de sentimentos nostálgicos e de emoções (SEDIKIDES ET AL, 2004).

Lembranças afetivas são componentes da memória e, por conta da relação com emoções, são mais prováveis de serem marcantes e relembradas (TUNG; RITCHIE, 2011). Quando eventos são incomuns, atípicos ou distintos, têm maior probabilidade de serem recordados (CHANDRALAL; VALENZUELA, 2013; TUNG; RITCHIE, 2011). Algo que produz memórias únicas e intensas provoca maiores respostas de recordação (HOLBROOK, 1993; REDER ET AL, 2002) e, quando positivas e especiais para o indivíduo, levam à nostalgia pessoal (MERCHANT ET AL, 2011).

Experiências turísticas memoráveis, portanto, são experiências de turismo positivas recordadas depois que um evento ocorreu em uma viagem (KIM ET AL, 2012). Elas têm importância por garantirem competitividade ao local de turismo, ao aumentarem a intenção de revisita e sua recomendação por comunicação boca a boca (WOODSIDE ET AL, 2004).

De acordo com Hoch e Deighton (1989), experiências de compra anteriores são percebidas como detentoras de credibilidade, já que a informação é obtida pela própria vivência e aprendizado, garantindo envolvimento e motivação para uma recompra. Para gerar compra futura, considerando uma visita a um local de turismo, é importante que empresários da indústria facilitem a criação de momentos memoráveis positivos (KIM ET AL, 2012). 
Somado a essa pretensão de aumentar intenção de consumo, a demanda crescente por experiências únicas e memoráveis no turismo exige do marketing atenção a preferências dos consumidores e ao seu processo completo de consumo (DUNAN; MATTILA, 2005; OH ET AL, 2007), já que oferecer somente produtos diferenciados e de qualidade percebida não é mais suficiente (DUNAN; MATTILA, 2005).

Há maior interesse em repetir algumas experiências memoráveis quando certos elementos-chave são garantidos. Mantidas determinadas condições importantes do evento original, há maior probabilidade de turistas retornarem a um determinado local (ZAUBERMAN ET AL, 2008). No entanto, não há consenso na literatura sobre como criar uma experiência marcante para o consumidor, que seja capaz de gerar memórias e sentimentos nostálgicos positivos. Estudiosos apontam que cada indivíduo relembra experiências de uma forma diferente e atribui a elas a característica de ser "especial" de forma subjetiva (ZAUBERMAN ET AL, 2008). Mesmo que serviços, atividades ou eventos equivalentes sejam vivenciados por duas pessoas, elas podem interpretar de maneiras diferentes, de acordo com seu envolvimento com o evento em níveis emocionais, físicos, espirituais ou intelectuais (TUNG; RITCHIE, 2011). Entendendo que "diferentes tipos de pessoas podem desejar diferentes formas de experiências turísticas", dependendo do relacionamento anterior com o local (COHEN, 1979, p. 180), diversos estudos foram conduzidos para identificar fatores com maior possibilidade de serem relembrados e que, por isso, têm maior relevância e influência na escolha de um local de destino (CHANDRALAL; VALENZUELA, 2013; GORDON，2013; KIM，2014; LEE，2015; TUNG; RITCHIE, 2011).

Para Tung e Ritchie (2011), quatro dimensões representam os aspectos nos quais momentos tornam-se memoráveis para turistas: afeto, expectativas, efeito das consequências e lembrança. O afeto está associado a emoções positivas e sentimentos bons atrelados à experiência. As expectativas referem-se a reações relacionadas à satisfação das intenções iniciais, além das surpresas positivas obtidas durante a viagem. Consequências envolvem interações sociais durante a viagem, não necessariamente com os companheiros de viagem, mas o contato com outras pessoas conhecidas no destino. A aquisição de novos conhecimentos sobre cultura local, idioma e estilos de vida, assim como o aprendizado e 
autoconhecimento, quando experiências vividas mudam estilo, crenças e perspectiva de vida, também fazem parte. Por último, a lembrança corresponde a esforços e ações, durante e depois da viagem, para relembrar o vivido no destino, como contar histórias, mostrar fotografias e comprar souvenirs. Tung e Ritchie (2011) levantaram também a intenção de revisita, a vontade de viver a experiência novamente e, em alguns casos, a intenção de retornar com pessoas diferentes, que não participaram da primeira visita.

Chandralal e Valenzuela (2013) identificaram temas que antecedem uma experiência turística memorável e chegaram a nove pontos centrais. O primeiro, significância percebida, corresponde às memorias de experiências com resultados pessoalmente enriquecedores e significativos, como o desenvolvimento de amizade com outros viajantes ou com moradores locais e estreitamento de laços com as companhias de viagem; aquisição de conhecimento e de capacidade intelectual; autodescoberta e mudanças pessoais; e promoção de qualidade de vida, divertimento e conhecimento para a família. Identificaram também oportunidades para interação com outros turistas e moradores locais, em que os elos entre indivíduos marcam a viagem, entretanto, não se estendem a longo prazo.

As oportunidades percebidas para contato com autênticas experiências locais são importantes para a criação de memórias, englobando o estilo de vida, culinária, cultura e linguagem dos residentes no destino. Chandralal e Valenzuela (2013) consideram como antecedente a importância percebida de algumas experiências, em termos de exclusividade e reputação, como atrações famosas, locais de reconhecida beleza natural, atividades difíceis de serem repetidas ou caras e realização de sonhos. Quando há novidade, sensação de realização de coisas diferentes e novas e surpresas ou incidentes não planejados, há alta probabilidade de o fato ser memorável. Além disso, a hospitalidade percebida na ajuda e na generosidade da recepção dos residentes, bem como o profissionalismo e as qualidades dos guias locais impressionam turistas. Por último, emoções positivas compõem a parte afetiva da memória autobiográfica de uma viagem. Embora os entrevistados por Chandralal e Valenzuela (2013) não revelassem intenção de revisitar os locais visitados, estão dispostos a recomendar para amigos e familiares. 
Turistas podem alterar suas decisões futuras em relação a consumo de viagem, com base em experiências vividas anteriormente no próprio local. $\mathrm{O}$ vivenciado durante a viagem é forte influenciador de comportamento futuro por ser gerador de experiências memoráveis (KIM, 2014). Para Kim (2014), os turistas são levados a decidir por um destino ou por atividades turísticas com base em atributos do local que, no decorrer da viagem, tornam-se componentes da experiência.

Para Kim (2014), os atributos de um destino que potencialmente promovem experiências turísticas memoráveis são a cultura local, a variedade de atividades, a hospitalidade, a infraestrutura, a gestão do ambiente/destino, a acessibilidade, a qualidade dos serviços, a geografia física, o envolvimento com o local e a superestrutura. A escala de medida dos atributos do destino em relação à criação de experiências memoráveis de Kim (2014) pode ser utilizada como forma de avaliar satisfação dos visitantes. De posse dos resultados, os empresários podem direcionar seus esforços de marketing para ajustar o desempenho de algumas dimensões especificas e, assim, aumentar a competitividade do local frente aos concorrentes (KIM, 2014).

Lee (2015) adotou como dimensões de experiências memoráveis no turismo o hedonismo, o envolvimento, a cultura local, o relaxamento, a significância, o conhecimento e a novidade. Em estudo sobre uma antiga estação de trem reconstruída e inaugurada como restaurante em Taiwan, houve correlação positiva entre nostalgia e experiências memoráveis no turismo, tendo o sentimento nostálgico efeito mediador sobre as emoções pessoais e experiências marcantes.

Gordon (2013) estudou o surgimento de emoções e memórias no contexto de turismo de esporte, identificando que algumas estruturas ou atributos do espaço (como estádios, cidades, estados, países, entre outros) servem como âncoras e despertam reflexões sobre memórias e emoções ali vividas. Gordon (2013) identifica correlação positiva entre experiências memoráveis com dimensões da nostalgia, confirmando que a capacidade de refletir sobre memórias passadas e significativas provoca sentimentos nostálgicos (SEEHUSEN ET AL, 2013). 


\section{2 . \\ Nostalgia}

A nostalgia, identificada em 1688 por Johannes Hofer, era entendida como uma doença potencialmente fatal, com sintomas de melancolia extrema, que atingia soldados e mercenários ao ficarem longe de suas casas por muito tempo. A origem da palavra confirma essa primeira atribuição negativa: nostos, voltar ao lar, e algos, condição de dor (BROWN, 2001).

Aos poucos, as conotações médica e militar foram sendo desconsideradas e, em 1798, Kant fez importante contribuição para a mudança na compreensão do termo. Para ele, nostalgia é a ânsia pela infância perdida (BROWN, 2001). A saudade é de um momento no tempo, não mais de um lugar, contrapondo-se à definição anterior.

Somente nos anos 1950 a palavra passou a ter o significado de perturbação emocional, que nasce de recordações de tempos passados, podendo até ser severa, mas não mais atrelada a uma condição fatal (BROWN, 2001).

Apesar de ainda ser caracterizada como um aspecto negativo e como "doença ou tristeza profunda, causada pelas saudades da pátria" pelo Michaelis Moderno Dicionário da Língua Portuguesa (2009), a nostalgia pode também remeter a sentimentos positivos (STEPHAN ET AL, 2014), ao preencher necessidades de pertencimento social (SEEHUSEN ET AL, 2013; WILDSCHUT ET AL, 2010) e elevar tanto a conectividade entre membros de um grupo com memórias comuns, quanto o senso de que compartilham os mesmos valores (BELK, 1988; CUI, 2015; LASALETA ET AL, 2014; ZHOU ET AL, 2012).

Além de reforçar os laços sociais, elemento essencial para a saúde física e psicológica dos indivíduos (WILDSCHUT ET AL, 2010), a nostalgia é considerada como positiva quando o conteúdo das memórias que a geram promove senso de significado para a vida presente, geralmente relacionadas a experiências marcantes do passado (ROUTLEDGE ET AL, 2011). Unindo os dois aspectos, um indivíduo tende a reduzir seu propósito de vida quando se sente excluída socialmente (STILLMAN ET AL, 2009).

A reflexão sobre aspectos nostálgicos aumenta a autoestima (WILDSCHUT ET AL, 2010) e prepara para responder a potenciais ameaças à autoestima e a seu 
bem-estar pessoal, ao ajudar na construção do senso de positividade e na visão dos atributos do eu pelos próprios indivíduos (VESS ET AL, 2012).

Considerada por Belk (1990, p.670) como "estado de humor melancólico que pode ser incitado por um objeto, uma cena, um cheiro ou uma música", a nostalgia também pode ser interpretada como uma emoção predominantemente positiva (SEDIKIDES ET AL, 2004; STEPHAN ET AL, 2014), relacionada à “interação com pessoas ou eventos importantes" (WILDSCHUT ET AL, 2010. p.988), que nasce da reflexão saudosa de um momento anteriormente vivido pelo indivíduo e que nele gera "preferências por pessoas, locais ou coisas que eram mais populares ou comuns em momento em que era mais novo" (HOOLBROOK; SCHINDLER, 1991. p.330).

Emoção é "uma forte reação afetiva a uma pessoa, experiência, mensagem ou situação" (PIETERS; RAAIJ, 1988. p.254) que é, geralmente, relacionada a uma causa ou percepção de uma situação específica (CLORE ET AL, 1987). A nostalgia é, portanto, considerada uma emoção (SEDIKIDES ET AL, 2004).

Havlena e Holak (1991) sugerem que a nostalgia é uma emoção que se refere a período anterior da vida de um indivíduo, baseando-se na recordação tendenciosa ou seletiva de experiências passadas, acreditando que devem ter sido por ele vividas.

Posteriormente, Holak, Havlena e Matveev (2006) reforçam que a nostalgia atrelada a um momento pode ser produzida mesmo por quem não o viveu, podendo ser compartilhada socialmente. Assim, quatro diferentes classificações são propostas pelos autores:

- Nostalgia pessoal: relacionada diretamente a experiências pessoais e memórias individuais;

- Nostalgia interpessoal: não originada diretamente de experiências pessoais, mas de memórias comuns, transmitidas socialmente, como por pais ou avós;

- Nostalgia cultural: envolve experiência direta, mas as lembranças abrangem experiências que marcam semelhança considerável entre os membros de um grupo. É um sentimento despertado para assemelhar-se a outros dentro de sua subcultura; 
- Nostalgia virtual: não originada diretamente de experiências pessoais, mas de livros, vídeos e materiais que apresentam memórias de um grupo, com que não necessariamente a pessoa tem conexão.

Dann apresentou a tipologia "push-pull” em 1977 (YOON; UYSAL, 2005) e, posteriormente, Crompton (1979) a desenvolveu, identificando melhor a participação de motivos sociopsicológicos na decisão de compra.

Para esse framework conceitual, os consumidores são levados a tomar decisões de consumo por motivação originada por forças intrínsecas e são atraídos por atributos do local de destino (CROMPTON, 1979). Os motivos "pull" são considerados fatores externos a um consumidor, cognitivos (representações mentais como conhecimento e crenças) e situacionais. Estão mais ligados a características dos destinos turísticos e como elas são percebidas pelo consumidor, como a existência de praias, parques, entretenimento, atrações culturais e históricas, experiências de culinária, entre outros. Por outro lado, os motivos "push" são forças internas de um indivíduo, como seus desejos e necessidades, associados a emoções e a instintos, como o escapar da rotina, encontrar relaxamento, buscar prestígio, conhecimento próprio, aventura, interação social, conhecer o novo e o sentimento nostálgico (CROMPTON, 1979). Desta forma, no contexto do turismo, a nostalgia pode ser um importante estímulo na decisão de visita de um local, especialmente por ser capaz de conectar o indivíduo com o ambiente e resgatar memórias marcantes (CHEN ET AL, 2014).

O sentimento nostálgico pode ser classificado em três tipos (BAKER; KENNEDY, 1994): nostalgia real (ligada a memórias pessoais e autobiográficas, com relação a experiências individuais), nostalgia simulada e nostalgia coletiva (não vivida pelo próprio turista, mas transmitida por fantasia ou história contada a ele).

Neste trabalho, o termo "nostalgia" é adotado como o sentimento gerador de preferência (gosto, atitude positiva ou emoção favorável) por pessoas, locais, experiências ou coisas, que eram mais populares ou comuns quando o consumidor era mais novo ou em momentos em que foram compartilhados, por seus grupos de referência ou por meios de comunicação. É uma força interna que gera reação a um dado estímulo de afeto, sobre a qual o indivíduo tem pouco controle direto e 
cujas respostas são sentidas fisicamente, por meio de reações e alterações no estado emocional (PIETERS; RAAIJ, 1988).

Em busca de experiências prazerosas, é possível que haja intenção de reprodução das atividades do passado e valorização de posses ou experiências que relembrem aquele período (BELK, 1988; BAKER; KENNEDY, 1994; HOLBROOK, 1993). Como o turismo é, geralmente, um consumo hedônico, na busca por prazer, diversão, entretenimento e fantasia, assume-se que aspectos nostálgicos podem ser compreendidos como uma motivação na decisão de um destino de viagem e, também, de sua revisita (CHEN et al, 2014). 


\section{3 \\ Método}

Conduziu-se uma pesquisa exploratória, por meio de entrevistas em profundidade baseada em métodos da filosofia fenomelógica adaptadas à pesquisa do consumidor (THOMPSON ET AL, 1989). Para fazer inferências sobre as maneiras como experiências memoráveis que provocam sentimentos nostálgicos ligados a locais de turismo manifestam-se e suas dimensões, o método permite maior flexibilidade na coleta de informações profundas sobre vivências no turismo (ZIAKAS; BOUKAS, 2013). O pesquisador ouviu relatos dos participantes para, em seguida, construir um entendimento acerca do tema em estudo (CRESWELL, 2007) e, inclusive, propor pontos para estudos futuros.

\section{1.}

\section{Seleção dos Entrevistados}

Foram entrevistadas quinze pessoas, acima de 30 anos, já que há maior tendência nostálgica nesse grupo etário (BENAZZI, 2000), tendo em vista que os consumidores, à medida que vão ficando mais velhos, procuram com maior força por experiências intangíveis que os liguem ao passado (RUSSEL, 2008), como o turismo (LEHTO ET AL, 2004).

A seleção foi feita por julgamento, com a colaboração inicial de funcionários de agências de turismo, que recomendaram clientes com relação com o fenômeno estudado, assim como fizeram Ziakas e Boukas (2013). Não houve a necessidade de um padrão ou elemento em comum entre os entrevistados como condição para a participação do estudo, considerando a intenção de obter um escopo mais amplo de perfis. 


\begin{tabular}{|l|c|}
\hline Nome Fictício & Faixa Etária \\
\hline Bianca & 30 a 39 anos \\
\hline Carlos & 30 a 39 anos \\
\hline Carlos Eduardo & 30 a 39 anos \\
\hline Cíntia & 30 a 39 anos \\
\hline Cristina & 50 a 59 anos \\
\hline Gustavo & 40 a 49 anos \\
\hline Jorge & Acima de 60 anos \\
\hline Maíra & 30 a 39 anos \\
\hline Marcela & 30 a 39 anos \\
\hline Olivia & 30 a 39 anos \\
\hline Patrícia & 50 a 59 anos \\
\hline Ricardo & Acima de 60 anos \\
\hline Roberta & 40 a 49 anos \\
\hline Soraia & 50 a 59 anos \\
\hline Victor & 40 a 49 anos \\
\hline
\end{tabular}

Tabela 1 - Lista de Entrevistados

Creswell (1998) recomenda que, para um estudo fenomenológico, sejam realizadas, ao menos, dez entrevistas longas. Assim, por saturação, foram entrevistados quinze indivíduos. As entrevistas continuaram até que os entrevistados "deixassem de introduzir novas perspectivas ao tópico de estudo" (GROENEWALD, 2004. p. 12).

\section{2. \\ Condução das Entrevistas}

Por meio de agendamento com os participantes, após apresentação da intenção de um estudo acadêmico, foram conduzidas as entrevistas em profundidade em local em que se sentiram confortáveis: em suas residências, em locais de trabalho ou em cafeterias. Cada entrevista teve duração de cerca de uma hora. Os relatos foram gravados, mediante autorização prévia do entrevistado, com a garantia do entrevistador de que as informações eram confidenciais, para que fosse minimizada a desconfiança e, assim, fossem sinceros (GROENEWALD, 2004).

Thompson, Locander e Pollio (1989) e Creswell (1998; 2007) recomendam que entrevistas conduzidas na tradição fenomenológica, como adotada aqui, são relevantes para estudar o comportamento de pessoas e suas experiências 
(fenômeno) da maneira como são vividas e percebidas. A interpretação ocorreu somente baseada no que o indivíduo apresentou sobre o fenômeno, de forma consciente (GROENEWALD, 2004; HYCNERM, 1999).

Sem roteiro, foi feita uma questão inicial somente ("Fale-me sobre viagens."), evitando que fossem levantadas perguntas a priori relacionadas ao tópico de estudo pelo entrevistador. Neste primeiro momento, buscou-se a percepção dos entrevistados sobre viagens. A condução das entrevistas foi definida pelo entrevistado, criando-se situação em que os respondentes tivessem liberdade para contar com profundidade suas experiências de turismo. As perguntas surgiram de modo natural, em forma de diálogo, incentivando descrições e relatos verdadeiros e detalhados sobre como as coisas aparecem para as pessoas (THOMPSON ET AL, 1989).

Thompson, Locander e Pollio (1989) recomendam que seja evitado o uso de perguntas do tipo "Por quê?", reduzindo a percepção de um papel invasivo por parte do entrevistador e, como consequência, reduzindo as respostas defensivas do entrevistado e a necessidade de racionalização das experiências, deixando que a interpretação fique somente a cargo do pesquisador. É importante que os relatos sejam sinceros, partindo do princípio de que esse tipo de entrevista deve levar em consideração a descrição das experiências com a maior riqueza de detalhes possível, tratando o fenômeno em seu contexto dinâmico e pela perspectiva das pessoas envolvidas, pelo ponto de vista do entrevistado (HYCNERM, 1999).

\section{3. \\ Explicitação dos Dados}

A tradição fenomenológica prefere adotar "explicitação de dados" no lugar de "análise de dados", reforçando que, nesta etapa, há uma investigação dos aspectos que constituem o fenômeno, mas que o senso do todo é mantido (GROENEWALD, 2004; HYCNERM, 1999).

Os relatos gravados foram escutados, transcritos e lidos até que se tornassem familiares (HYCNERM, 1999). Em seguida, foram categorizados por padrões e temas comuns e classificados em um sumário consolidado, com estrutura que permita observar padrões e diferenças entre grupos e indivíduos. 
O método de explicitação adotado faz uso dos termos utilizados pelos respondentes, e não somente de termos conceituais já existentes e de conhecimento do pesquisador (THOMPSON ET AL, 1989; THOMPSON ET AL, 1990). Como orientado por Thompson, Locander e Pollio (1989), as dimensões levantadas pela literatura foram estudadas para esta classificação. No entanto, foram também mencionadas novas categorias ressaltadas pelos entrevistados. Houve idas e vindas entre a literatura e os relatos mas em um segundo momento, já que o critério metodológico prioriza o nível de relato das experiências com as categorias e as definições apresentadas pelos entrevistados para cada conceito, não aquelas definidas culturalmente, visto que "experiências vividas podem nem sempre honrar os limites conceituais padrão e, portanto, deve ser entendido o conteúdo relativo ao contexto de vida específico no qual ele emerge" (THOMPSON ET AL, 1990. p. 347).

Nas falas dos entrevistados, estão contidos eventos, valores, regras, crenças, conflitos, motivações, atitudes e aspectos indicadores de possíveis relações. A interpretação do conteúdo das entrevistas não incorporou inferências e/ou hipóteses prévias, ou seja, na explicitação dos relatos o pesquisador teve de se ater somente ao que foi transcrito, sem pré-julgamentos (THOMPSON ET AL, 1989; THOMPSON ET AL, 1990).

Também como recomendação de Thompson, Locander e Pollio (1989), foi criado um grupo interpretativo para esta etapa de análise. Ele foi composto pelo pesquisador e seu orientador. A intenção foi minimizar as concepções iniciais de cada um, atendo a explicitação dos dados somente aos relatos e garantindo que a interpretação estava no nível da experiência do respondente, comprovando com trechos da transcrição. A visão de diferentes indivíduos auxilia, fazendo com que todos os padrões existentes nas entrevistas sejam identificados.

Nas entrevistas, foram reveladas algumas dimensões comuns, levando a identificação de padrões de significados que formam um pano de fundo na forma como são manifestadas experiências memoráveis que provocam nostalgia em relação a locais de turismo. As principais categorias que emergiram nos dados foram momentos de interação com amigos, familiares ou parceiros românticos; expectativa em relação ao local de viagem e realização de sonhos. Tais dimensões foram mencionados na literatura existente como potenciais geradores de 
momentos memoráveis em viagem, mas o presente trabalho observou haver relação com o desencadeamento de experiências nostálgicas.
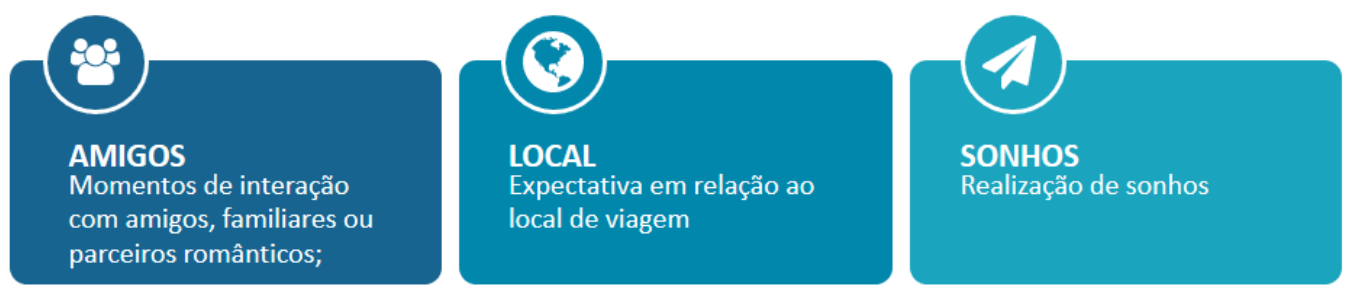

Figura 1 - Dimensões identificadas nos dados

\section{4.}

\section{Limitações do Método}

A pesquisa exploratória não busca medir estatisticamente ou expressar resultados em números. Desta forma, o conhecimento produzido a partir deste estudo não permite generalizações, visto que é fruto de inferências acerca de relatos de cada um dos indivíduos entrevistados. Também, a abordagem fenomenológica utilizada produz análises subjetivas por parte do pesquisador, sujeitas a diferentes interpretações. Por outro lado, sugere, ao fim, novos pontos para estudos futuros.

O consumidor não é sempre capaz de verbalizar suas ações ou de racionalizar seu comportamento até a decisão de consumir algo. O método empregado, ainda que adequado para o objetivo requerido, necessita uma atenta explicitação de dados, para que sejam compreendidos os elementos emocionais e contextuais dos relatos, mesmo que não explícitos de imediato pelo entrevistado. 


\section{4 \\ Resultados}

Muitas experiências marcantes foram apresentadas, contendo momentos de emoção, alegria, frustração, satisfação e amor. No entanto, não foram todos as vivências em viagens que puderam ser enquadradas como memoráveis, considerando que essas são experiências positivas de turismo recordadas depois que um evento ocorreu em uma viagem (KIM ET AL, 2012). Tampouco todas as vivências e experiências memoráveis foram compreendidas como geradoras de sentimentos nostálgicos.

Experiências memoráveis que remetem a sentimentos saudosos não parecem ser necessariamente relacionadas a locais ou destinos turísticos. Os entrevistados podiam esquecer o local exato e a data de visita, mas não esqueciam as lembranças e as emoções vividas. São as experiências, especialmente as sensações vividas, que têm papel essencial em tornar nostálgica uma experiência memorável.

As dimensões levantadas foram momentos de interação com amigos, familiares ou parceiros românticos; expectativa em relação ao local de viagem e realização de sonhos. As categorias identificadas não obrigatoriamente estavam descritas na literatura, visto que o método adotado leva em consideração categorias que emergiram nas entrevistas.

\section{1.}

Momentos de interação com amigos, familiares ou parceiros românticos

Grande parte dos entrevistados manifestou como marcante o estreitamento de laços e a aproximação com os companheiros de viagem. Ao apresentarem essas ligações e momentos vividos juntos com amigos, familiares ou parceiros românticos, foram reveladas respostas afetivas espontâneas e sentimento nostálgico. 
Chandralal e Valenzuela (2013) apontaram o fortalecimento de proximidade das companhias de viagem como um ponto que antecede uma experiência turística memorável. As entrevistas confirmam, mas mostraram que a dimensão é, também, geradora de nostalgia.

A reflexão saudosa de viagens com boas companhias e os momentos de agradável convívio caracterizaram boas recordações e emoções positivas de treze entrevistados dos quinze, relacionadas à experiência de reunião do grupo, sem necessariamente ela estar atrelada a um local específico.

Carlos Eduardo: Acho que essas viagens me trazem vontade de voltar mais pelas pessoas que estavam lá e pelo grupo ter se reunido, do que pelo local em si.

Experiências de conquistas, aprendizado e superação foram relatadas por nove entrevistados. Somente as vividas com a companhia e com o auxílio de amigos, apresentaram características nostálgicas. A parceria nestes momentos importantes e marcantes tornavam-nos mais especiais, pelo reforço do sentimento de amizade e pela possibilidade de compartilhamento da recordação, gerando senso de pertencimento.

De fato, viagens com amigos foram manifestadas como um ponto gerador de boas lembranças. A sensação de proteção e grande carinho mútuo gerava momentos leves e divertidos, facilitando com que estivessem à vontade uns com os outros no local de turismo. Pelos relatos, os principais momentos em que essas emoções estiveram em evidência configuraram-se como experiências memoráveis e nostálgicas.

Pode-se citar a entrevistada Marcela, em que o companheirismo e a ajuda dos amigos durante uma viagem à Chapada Diamantina modificaram sua percepção sobre a experiência no local, contada com grande emoção.

É nessas horas que você vê que o quanto as pessoas que estão com você realmente te apoiam. (...) E, nessas horas que você vê que as pessoas estavam realmente preocupadas não só em chegar bem, mas que todo mundo chegasse junto. (...) Quando a gente chegou, a gente ficou muito emocionado e fez uma oração. Foi super lindo! Foi um momento das pessoas terem conseguido. (...) E foi uma superação! Eu tinha superado aquela barreira que eu achava que jamais ia conseguir ultrapassar! 
Uma experiência em viagem ou em um local específico, além de ser capaz de provocar sentimentos saudosos, pode reforçar o significado de amizade e de amor, evidenciando a reciprocidade de afeição, de confiança e de ajuda mútua.

Quando se trata de relações de amor, há rituais tradicionais envolvidos que, possivelmente, promovem lembranças especiais. Significados simbólicos para determinados eventos ou atos são atribuídos e compartilhados por gerações e por indivíduos de um mesmo grupo. Sua valorização faz com que as pessoas planejem momentos e os contem posteriormente, celebrando-os como grandes conquistas. Nas entrevistas, alguns desses acontecimentos em viagens, como noivado, casamento, viagens românticas e comemorativas e lua-de-mel, foram relatados.

O ritual do noivado torna o pedido de casamento um momento especial para o casal e costuma promover uma recordação positiva e duradoura. Um local de turismo pôde ter seu significado modificado após este momento ter sido ali vivido. Mas a lembrança mais saudosa estava associada ao nervosismo, à emoção vivida e à demonstração de amor que a experiência representa para as duas pessoas. A nostalgia se fez presente no contentamento ao relatar e na reflexão saudosa do sentimento vivido.

A cerimônia do casamento é o ritual mais marcante relacionado à celebração da união e do nascimento de uma nova família. Experiências de casamentos em viagens (os “destination weddings") promovem lembranças muito positivas e repletas de aspectos nostálgicos. Mesmo que envolvida indiretamente, participar da celebração como madrinha fez com que Maira tivesse reações afetivas de amizade e amor ao relembrar o momento.

Foi super especial! (...) Eu vou lembrar muito desses momentos, do casamento deles, de como a gente se sentiu entrando na igreja para ficar pertinho e abençoar a amor deles, de como a galera estava curtindo nos hotéis. (...) Com certeza, Búzios e Friburgo não são mais os Búzios e Friburgo de antigamente.

Quando a entrevistada era a noiva, a experiência parece ser ainda mais memorável e as lembranças mais fortalecidas por saudosismo. Viver a celebração do seu amor em um destino turístico, assim como levar as pessoas mais especiais para compartilharem o momento, tornou tudo mais marcante. Olivia relatou: 
Não tenho palavras para descrever a saudade que eu sinto desse dia e a emoção que eu senti em reunir as pessoas que eu mais amava, as pessoas que foram importantes na minha vida inteira, num só final de semana. (...) Ver a alegria nos olhos de cada um dá uma saudade muito grande, me aperta o coração.

Assim como a celebração do casamento, relatos de viagens de lua-de-mel revelaram-se com potencial nostálgico, especialmente quando os momentos recordados estavam atrelados a sensação de relaxamento e de comemoração com o parceiro romântico.

Dada a grande representatividade dos rituais mencionados, as datas dos acontecimentos podem ser guardadas e gerar comemorações periódicas, reforçando a intenção de resgatar aspectos e sentimentos vividos no passado. Viagens românticas foram importantes marcos na vida de alguns entrevistados. Experiências fora da rotina, em locais diferentes, com o compartilhamento de sensações e dividindo aprendizado permitiram maior aproximação do casal e um convívio intenso, um importante passo para consolidar o relacionamento amoroso. Olivia continua:

A gente está num outro país, mas, ao mesmo tempo, a gente está com a gente - não precisamos de mais nada. Foi uma viagem que me marcou muito, porque mostrou a cumplicidade que eu e ele vamos ter para o resto da vida.

Em termos de companheiros de viagem, além dos amigos e amantes, as famílias foram constantemente mencionadas como fator marcante em viagens. Experiências de turismo recorrentes, como visitas a casas de veraneio da família, com a companhia de familiares, foram mencionadas e apontaram tendência a recordações nostálgicas. Percebe-se que emoções vividas ali geravam lembranças fortes e positivas, com intenção de revisita e vontade de reprodução futura. Quando não houve continuidade nas visitas, ou com a venda do imóvel, a saudade revelava-se ainda maior, pela impossibilidade de retorno e da reprodução das sensações vividas.

Foi presente nos relatos a busca por partilhar momentos semelhantes a experiências vividas antes, mesmo que viajando para outro destino ou visitando diferente local de turismo. Ainda que em nova configuração familiar (após a perda 
de algum parente ou a separação de casais), os relatos mostraram que existia um intuito de resgatar as emoções de viagens anteriores. Viver em família firmava-se como a intenção da visita de turismo em alguns casos, sem a relação com um ponto específico, mas com rotinas, atividades e emoções características de que o núcleo familiar havia vivido antes.

Nos relatos, houve procura por viajar para reviver sensações de antes. Até o planejamento de novos passeios já estava envolvido por sentimentos nostálgicos, com decisões embasadas na intenção de reviver as mesmas sensações. A nostalgia pôde surgir como principal fator motivacional de uma viagem. No caso de Patrícia, ficou clara a busca por unir os membros da família, cada vez em um local diferente, mas sempre juntos.

Claro que tem a questão de se divertir, mas é o fato de estar toda família junta que é o mais importante de tudo. (...) Então isso, para gente, é o que norteia a nossa viagem.

Relatos revelavam a intenção forte de sentir novamente as emoções de estar com a família, mas sem que houvesse interferência ou aspecto que impedisse tal reviver, como ilustrado por Ricardo.

Ricardo: Viagem é o momento em que eu esqueço todos os problemas esqueço o trabalho, esqueço o celular, esqueço tudo. Fico totalmente incomunicável, principalmente porque gostamos de viajar os quatro. Valorizamos estar a gente, a família. Não gostamos muito de grupos, porque se a democracia com quatro já é complicada, em grupos de doze é um conflito só!

Com o crescimento de uma nova geração e a natural independência na vida adulta, pais e filhos entrevistados relataram sentir falta de reviver o "momento em família", vendo nas viagens que juntos realizam uma forma de reproduzir experiências e sentimentos do passado.

O relacionamento, o envolvimento e o resgate de sensações comuns a outros momentos familiares fez com que o relato de Olivia fosse ilustrativo. Sua viagem com os pais e com a irmã era para comprar seu vestido de noiva, mas essa não foi a experiência turística que mais a marcou e que gerou nostalgia. 
E o que mais me marcou nessa viagem foi parecer que eu estava voltando no tempo, parecia que eu estava fazendo uma viagem de férias com os meus pais quando eu era novinha - não foi nem o meu vestido de noiva, mas foi o sentimento de estar nós quatro, juntos, e ser a mesma coisa que era há vinte e poucos anos atrás. Foi isso que me marcou: a gente se curtir.

Carregando tal característica nostálgica, as experiências em viagens com toda a família ficam mais marcantes e acabam por ser ainda mais valorizadas com o passar do tempo. As viagens longas com todos os familiares se apresentaram como mais raras do que antes. No entanto, para manterem a experiência compartilhada, alguns entrevistados buscaram alternativas, como viagens menores, para locais mais próximos e de fácil deslocamento, permitindo que a decisão fosse rápida e adequada a diferentes perfis de pessoas.

A nostalgia ligada a viagens familiares não foi manifestada somente no ato de contar a experiência para o pesquisador; ou no relato de como era a fase de planejamento de um passeio de turismo, lembrando de sensações antigas e tomando decisões para revivê-las; ou durante a própria visita a um local de turismo, recordando sentimentos de vivência anterior com aquelas pessoas. Os relatos apontaram que situações memoráveis em viagens ficam armazenadas na memória e, eventualmente, podem ser resgatadas ao serem apresentadas a algum estímulo. Algumas passagens cotidianas, como aspectos do ambiente (cheiros, gostos, visuais, etc.), são capazes de despertar reações psicológicas, como o afeto e sentimentos saudosos relacionados a locais de turismo, ilustrado pelos comentários de Cíntia.

Tem um desodorante específico que tem o cheiro de Araruama. Eu nem uso mais esse desodorante, mas, quando alguém chega e está usando esse desodorante, eu sinto o cheiro de lá! É muito engraçado! É que nem, também, tem purê de maçã. Purê de maça é uma coisa que eu não como, mas sempre tinha lá... Mini pizza me lembra de lá!

Em termos gerais, quando se trata de viagens de turismo, o resgate de momentos nostálgicos também pode ser obtido por fotografias, como citou Carlos.

Eu tiro muita foto, mas eu tiro foto por um motivo especifico: quando eu vejo a foto, eu relembro da viagem e vem o momento bom da viagem. (...) Eu vou passando e relembrando aqueles momentos que eu vivi. Então, é 
como se eu estivesse vivendo a viagem de novo, vai trazendo a viagem de novo.

A partir de um momento específico "congelado" em imagem, um sentimento nostálgico é produzido em relação a um período, local, pessoas e, principalmente, experiências. Essa observação está de acordo com Barthes (1980), que reforça que fotografias carregam significados, além de grande componente emocional de relação com o passado.

\section{2.}

\section{Expectativa em relação ao local de turismo}

A realização e o atendimento (ou superação) das expectativas prévias de um viajante foram pontos revelados nas entrevistas.

Tung e Ritchie (2011) identificaram as expectativas como uma das quatro dimensões que representam os aspectos nos quais momentos tornam-se memoráveis para turistas. Os relatos revelaram que elas podem gerar experiências memoráveis - algumas, inclusive, com potencial nostálgico. Essa dimensão é compreendida como reações relacionadas à satisfação das intenções iniciais, assim como às surpresas positivas obtidas durante a viagem ou a ida a um local de turismo, que vão além de expectativas assumidas durante o planejamento.

Ao planejar, uma pessoa tem uma meta prévia na qual se baseia para suas buscas e decisões. Notou-se que esse objetivo pode alterar-se ao longo da vida, de acordo com o desenvolvimento e amadurecimento de cada indivíduo.

Em cada etapa vivida, e para cada decisão de turismo tomada, expectativas são estabelecidas. Apesar de presentes nos relatos e serem potenciais influenciadores nas decisões de viagens futuras, os casos em que não houve atingimento da expectativa inicial proporcionaram momentos e recordações negativos. Por esse motivo, não foram considerados como experiências turísticas memoráveis. Por outro lado, o simples alcance da expectativa prévia sobre a visita a um local de turismo revelou a possibilidade de tornar tal momento inesquecível, porém não nostálgico.

Quando eventos são incomuns, atípicos ou distintos, têm maior probabilidade de serem recordados (REDER ET AL, 2002). O inesperado promoveu momentos especiais e lembrados com saudosismo e afeto nos relatos. 
Quando as experiências foram positivas, suas lembranças provocaram nostalgia pessoal (MERCHANT ET AL, 2011).

Da mesma maneira que Chandralal e Valenzuela (2013) afirmam que, quando há novidade, sensação de realização de coisas diferentes e novas e surpresas ou incidentes não planejados durante a viagem, há alta probabilidade de o fato ser memorável. Os relatos mostraram que, quando há novidade e surpresas, maior a possibilidade de o fato ser memorável e nostálgico. Alguns relatos podem ilustrar.

Marcela optou por uma viagem nacional para economizar, sem grandes expectativas sobre o destino. Com o namorado e amigos, foi para a Bahia. Depois de uma trilha na Chapada Diamantina, deparou-se, de forma inesperada, com a Cachoeira do Buracão. A sensação de surpresa a emocionou no momento em que viveu a inesperada experiência e, da mesma forma, quando na entrevista, justificou ter sido uma das viagens mais inesquecíveis que já fizera.

É muito bom, porque você vai indo aos pouquinhos, vai passando pelo canyon e você não vê a cachoeira. (...) Quando você vira, você vê aquele buraco enorme. (...) É um negócio surreal, é assustador! Com uma força sobrenatural! (...) Quando a gente viu, a gente começou a chorar de emoção! (...) Foi impressionante! Aquela queda monstruosa faz você se sentir pequeno no mundo por estar naquele lugar com aquela energia absurda de água de cachoeira.

Maíra admira paisagens e busca, em suas viagens, lugares com visuais paradisíacos. Mesmo tendo contado ter tido contato com vistas incríveis do Havaí, o que mais a marcou, emocionou ao contar, foi a surpresa que teve ao mergulhar perto do seu hotel, na ilha de Mauí.

Eu lembro que nessa ilha foi onde a gente mais ficou esperando ver o que vai acontecer, sem muitas programações. (...) Assim que a gente entrou no mar e afundou a cabeça na água, a gente viu uma tartaruga que era a metade do meu tamanho! E isso no quintal do hotel! Então, era uma coisa super inesperada que marcou a gente pra caramba! E isso só fez o meu namorado me falar: "Viu como é bom curtir as coisas aos poucos, sem ficar preocupada em dar check em todas as coisas e todos os programas que tem que conhecer nos lugares?" 
Um roteiro muito inflexível e pré-determinado impede que aconteçam incidentes positivos deste tipo. Nas decisões de viagem, foram citadas escolhas por locais pouco explorados como turísticos, não tradicionais. A busca pela imprevisibilidade encantou muitos entrevistados, surgindo, implicitamente, uma expectativa por algo que surpreendesse positivamente, mesmo não planejado.

Victor: Eu costumo não alimentar muita expectativa para evitar frustração. (...) É mais fácil a gente se encantar e ter uma satisfação muito grande, quando a gente alimenta pouca expectativa sobre o lugar. Eu costumo planejar pouco. Eu costumo planejar o básico. (...) Eu costumo me sentir mais livre e mais aberto a conhecer novas culturas se eu não tiver uma agenda muito fixa, para ter algo que eu não planejei e me surpreenda com o lugar.

Algumas das visitas a locais pouco convencionais, indicados por moradores locais durante a viagem, geraram momentos marcantes e lembrados com nostalgia. Especialmente restaurantes locais menos conhecidos por turistas foram lembrados com saudosismo, pelo serviço prestado além do esperado e pelo sabor único da comida oferecida. O vivido no local e fora das listas de roteiros tradicionais surpreendeu e tornou fácil a recomendação e a indicação para outras pessoas.

Carlos: Procuro coisas diferentes. Uma coisa é fato: eu não gosto de ficar só no lado turístico. (...) Prefiro visitar as outras coisas. Aí, você vai num restaurante pequeno, que não dá nada por ele! Aconteceu em Paris, eu fui num tipo pubzinho. Estava até vazio, tinham duas ou três pessoas. (...) E chegou lá o prato era excelente! Ai, depois, a gente voltou mais duas vezes lá. “Cara, não é possível que é tão bom!" (...) Foi surpreendente e eu geralmente recomendo. Eu, hoje, como acho que o mundo é muito grande, procuro não voltar a lugares que já fui porque tem vários lugares que eu não conheço e que gostaria de ir, mas eu indicaria para as pessoas, porque foi assim que eu consegui as melhores indicações. Enfim, você vai dando indicações e você tem interesse, porque o lugar é bacana e o negócio vai crescer para outras pessoas terem acesso àquilo que você teve.

Nos relatos, como o de Carlos, notou-se que há intenção de divulgação de locais de turismo a outros potenciais consumidores quando elas agradaram, quando superaram expectativas e quando promoveram boas e memoráveis experiências, lembradas com nostalgia. Mencionadas por nove entrevistados, as mídias sociais revelaram-se como forma bastante utilizada para a troca de 
informações sobre viagens, especialmente por meio de avaliações pós-compra, relatos de experiências por críticas online, fotografias publicadas e por meio de blogs e da interação virtual entre consumidores.

Além de desempenharem papel informativo na avaliação das alternativas existentes de consumo relacionado à viagem, inclusive sobre locais não tradicionais da rota turística de um destino com maior probabilidade de promover experiências agradáveis inesperadas, foi observado que acabam por influenciar nas futuras decisões, facilitando com que o consumidor consiga prever e imaginar comportamento e sensações ao optar pela visita. Tal constatação corrobora o estudo de Gretzel, Fasenmaier e O'Leary (2006), que resumiu a aplicação das mídias sociais nos três estágios de necessidade de comunicação e informação no consumo do turismo.

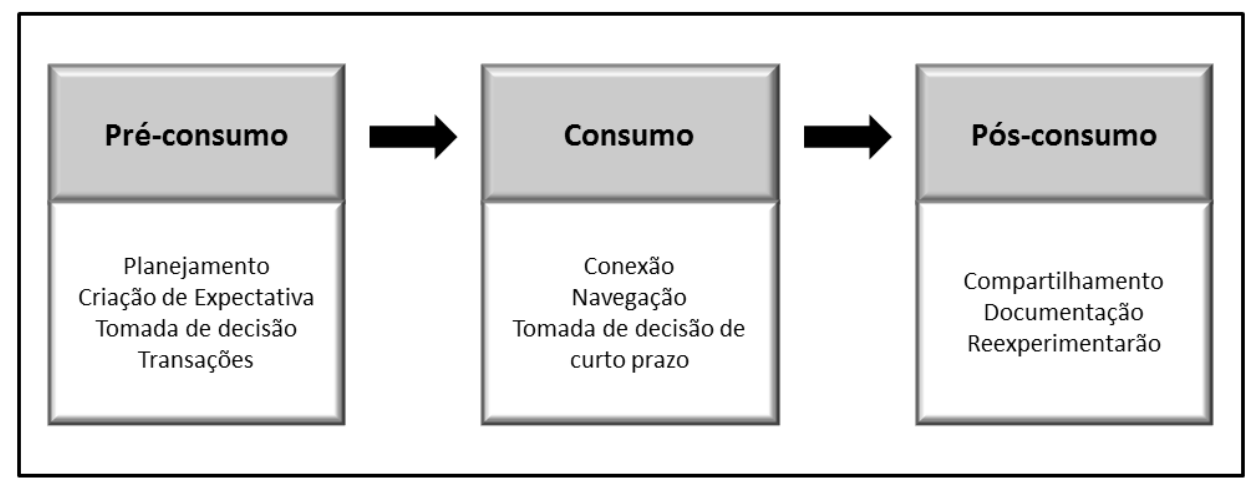

Figura 2 - Necessidade de comunicação e informação no consumo de turismo. (Adaptado de GRETZEL ET AL, 2006, p. 8)

Quando relatavam suas experiências de viagem, os entrevistados abordavam aspectos emocionais, como saudade, prazer, divertimento, realização, felicidade. Moore (2015) identificou que críticas online com maior utilidade para leitores que buscam informações sobre produtos hedônicos, adquiridos para atendimento de um desejo, por envolvimento emocional e com intenção de obtenção de prazer, adotam as reações vividas como ponto central das avaliações.

\section{3. \\ Realização de sonho}

Chandralal e Valenzuela (2013) consideram como um antecedente de uma experiência memorável a importância dada pelo viajante a algumas experiências exclusivas e com reputação reconhecida, como atrações famosas, locais de beleza 
natural reconhecida, atividades consideradas difíceis ou caras de serem repetidas ou a realização de um sonho.

Após anos de imaginação, de desejo e de intenção de estar em um local, a experiência da realização de um sonho, quando observada em experiências da viagem, agiu como gatilho de nostalgia, fazendo com que a sensação vivida no momento fosse contada com grande emoção e saudosismo.

Em termos de sonhos revelados nas entrevistas, visita à Disney representou um atingimento de objetivo em viagem. Em alguns casos, a visita foi há muito tempo, mas, ainda assim, estava forte na memória e foi relatada com emoção e entusiasmo.

Bianca: Orlando é uma cidade bacana e tal, mas o que eu lembro mesmo é da sensação de ver o castelo e de ver o espetáculo do Rei Leão. O Rei Leão me faz chorar! Quando eu vejo coisas relacionadas ao Rei Leão, eu tenho a cena na minha cabeça de quando eu fui ao cinema: eu, no meio da minha mãe e do meu pai. É especial!

O momento de chegada pareceu ter forte significado, marcando a circunstância em que o sonho tornava-se realidade.

Soraia: Eu me lembro que, quando eu cheguei no parque da Disney, eu chorei, porque eu só via a Disney nos gibis e filmes. Então, quando eu cheguei em frente ao castelo da Cinderela, eu falava: "Estou chorando de emoção. Eu jamais pensei que eu estaria aqui!".

Problemas eventuais, ou situações que dificultariam o convívio ou a satisfação em outro cenário, parecem não interferir quando se trata de uma experiência de concretização de sonho.

Marcela: A gente foi para Disney e, realmente, esta viagem foi a viagem dos meus sonhos! Ir para a Disney foi uma das melhores coisas que eu fiz na vida! (...) A sensação de entrar no Magic Kingdom é uma das coisas mais emocionantes que eu já vivi! (...) A gente não se incomodava nem um pouco em ficar na fila, em perrengue para entrar nos brinquedos, porque a gente estava se divertindo muito!

Pelos relatos, foi observada a sensação única de realização. Mesmo que sendo citada por diferentes entrevistados, foi comum nas entrevistas o reforço do 
sentimento vivido na Disney provocar saudosismo, não necessariamente relacionado com o lugar físico.

Sonho também pode ser levar alguém a um lugar que foi importante no passado. Mesmo sendo o mesmo cenário, foi possível perceber que a intenção de retorno não estava atrelada ao ambiente, mas à reprodução e compartilhamento de sensações e emoções vividas antes. Uma experiência lembrada com nostalgia gerava um sonho associado à intenção de revisita e, por sua vez, esse segundo momento no local também gerou nostalgia.

Cristina: Durante essa fase também da nossa filha crescendo, o nosso sonho era qual? Levar à Disney! Claro! (...) Toda a emoção que eu vivi sozinha, que eu vivi com meu marido, a gente viveu com a nossa filha! Ah... Foi ótimo! Nós vivemos uns dias maravilhosos. Foi sensacional! Uma viagem marcante!

Foi recorrente nos relatos o sonho de apresentarem outros lugares especiais já visitados para pessoas que amam. Uma fotografia, histórias contadas, um souvenir ou qualquer outra forma de apresentar ao outro o que se sentiu durante a experiência revelou-se menor do que reviver o fato acompanhada.

Nem sempre a nostalgia estava presente somente na realização de um sonho ligado ao retorno a um local. Em alguns casos, mesmo que a primeira visita não tenha gerado experiências inesquecíveis e nostálgicas, revisitar para realizar sonhos, pareceu ser relevante. Para Cristina, viver a experiência de ir a Portugal com os pais foi importante, gerando recordações nostálgicas pela emoção do outro e pelo sentimento de satisfação em poder proporcionar a eles momentos especiais.

Portugal era o sonho dos meus pais. Eu já tinha ido e tinha gostado, mas gostaria muito que eles também participassem disso. Então a gente foi, há dois anos atrás, com eles. (...) E eu senti uma felicidade danada! (...) O objetivo era esse: fazer com que eles fizessem a viagem que era o sonho deles. Se eles estavam felizes, eu estava feliz. Foi especial! 


\section{5 \\ Conclusões}

O trabalho teve como propósito identificar categorias de experiências de viagem capazes de desencadear nostalgia pessoal. Eventos e percepções comuns entre os relatos revelaram que emoções têm papel essencial em tornar uma experiência turística memorável em nostálgica, quando associadas a momentos de interação com amigos, familiares ou parceiros românticos, a expectativa em relação ao local de viagem e a realização de sonhos. Não parecem, entretanto, estar ligadas aos locais ou destinos turísticos em si.

O estreitamento de laços e a proximidade com companheiros de viagem, reforçados pelo convívio intenso com o grupo, e experiências de conquistas, aprendizado e superação compartilhadas com amigos e capazes de evidenciar sentimentos de proteção e carinho mútuos são exemplos de momentos que se tornaram lembranças saudosas. Além disso, momentos em local de turismo que ressaltam as sensações de viver em família promovem nostalgia e são ainda mais valorizados, com o passar do tempo, pelos familiares.

Ultrapassando expectativas prévias sobre um local, as surpresas nele presentes são reconhecidas como gatilhos nostálgicos. Eventos inesperados, incomuns, atípicos ou distintos desenvolveram momentos especiais que são lembrados com afeto nos relatos.

A realização de um sonho em viagem atribui ao momento emoção forte e memorável. Não somente a ideia de concretizar objetivos individuais, mas apresentar um local muito desejado a alguém importante, compartilhando a experiência, a torna fonte de recordações repletas de saudosismo.

Sentimentos relacionados às dimensões identificadas são armazenados na memória, sendo a eles atribuídas atitudes positivas e relevante importância. Quando acessados pelo consumidor, intencionalmente ou não, promovem lembranças que acionam sentimentos nostálgicos e geram a intenção de reprodução das emoções. A ação de reviver sensações anteriores pode ser alcançada por meio de uma viagem, portanto, o consumo com característica 
hedônica e a busca por prazer pela realização de uma experiência semelhante atuam como solução para o atingimento da meta do consumidor.

Coerente com o framework conceitual de Crompton (1979), a nostalgia configurou-se como um motivador na decisão de viagem. Os resultados aqui obtidos apontaram que aspectos nostálgicos podem impulsionar a busca por sensações anteriormente vividas, mas não revelaram que os atributos do local são essenciais para isso. Apesar de alguns indivíduos assumirem que não deve haver o retorno ao local de viagem, as lembranças das sensações ali vividas detêm papel influenciador e facilitador para novas experiências turísticas. A busca por viagem pode tentar reproduzir atividades do passado e estar ligada à valorização de posses ou experiências que o relembrem aquele período (HOLBROOK, 1993; BELK, 1988), trazendo a sensação de que o presente pode ser semelhante ao passado.

Foi reforçada a compreensão de que as decisões de consumo de viagem não estão somente associadas a processos gerados por aspectos racionais, sem a participação de componente emocional. Aspectos afetivos atrelados à nostalgia, obtidos por meio de recordação de sensações anteriormente vividas em viagens, são motivadores de reprodução de experiências e de indicação a amigos e conhecidos.

A nostalgia revelou-se também nas etapas de planejamento de visita a um local de turismo. Há diferentes aplicações gerenciais possíveis para garantir que empresários do setor de turismo ajustem suas decisões, aumentando as chances de influenciarem positivamente o comportamento do consumidor, além de promoverem satisfação, fator que impacta a intenção de revisita (JAVIS ET AL, 2016) e, assim, a lealdade. Yoon e Yysal (2005) entendem por lealdade no turismo tanto a revisita ao local quanto as recomendações feitas à família e a amigos ou à rede de relacionamento.

Em termos de comunicação com o consumidor, ela pode ter conteúdo associado ao resgate de sensações ali vividas, ao ser direcionada a antigos visitantes. Quando se trata de parceiros românticos, entendendo e armazenando informações sobre o motivo da primeira visita, empresas (como hotéis e restaurantes) podem sugerir a possibilidade de reprodução das emoções, aproveitando datas comemorativas. Buscando o inesperado e a surpresa, o hotel pode oferecer o mesmo quarto da última visita ou o restaurante pode ceder a 
mesma mesa, estimulando recordações positivas sobre a atenção na prestação do serviço.

Sabendo que a produção de conteúdo na internet passou a ser mais constante (KAPLAN; HAENLEIN, 2010), que o uso de mídias sociais é importante para o engajamento e aproximação dos clientes com empresas de turismo (CABIDDU ET AL, 2014; DIJKMANS ET AL, 2015) e que, nos relatos, seu uso revelou-se como fonte de informação utilizada no planejamento e na experiência turística de diferentes perfis, as empresas devem adotar meios de comunicação ao se reportarem a turistas, desenvolvendo perfis nas redes sociais.

Houve aumento da popularidade de plataformas digitais que adotam o compartilhamento de imagens - por exemplo, Facebook, Instagram, SnapChat, Tumblr, Flickr (SENFT; BAYM, 2015). Com isso, as pessoas passaram a ter acesso à amplitude de ferramentas de redes sociais que valorizam também a apresentação de conteúdo visual ou audiovisual, como fotografias e vídeos, facilitando que reforcem histórias contadas e permitindo maior compreensão na transmissão de experiências (MUNAR; JACOBSEN, 2014). As fotografias foram mencionadas nas entrevistas como fonte nostálgica e, deste modo, o uso dessas redes sociais por locais de turismo pode facilitar o resgate de sensações positivas favoráveis à visita. A oferta de fotos como souvenir do local é também sugestão de meio de incentivar recordações de sentimentos vividos.

Estudo realizado por Moore (2015) indica que há a intenção dos consumidores em contribuir voluntariamente com informações sobre experiências próprias. Na indústria do turismo, comentários online são administrados por sites e aplicativos de avaliação dos serviços do setor - alguns bastante populares, como o TripAdvisor (LIU; PARK, 2015). É recomendável que profissionais do ramo estejam presentes também nas principais plataformas de avaliações, realizando boa gestão sobre opiniões divulgadas na internet, analisando o conteúdo gerado pelos consumidores nas mídias sociais para providenciar melhorias quando necessário. Entendendo que os relatos das experiências de viagem estavam mais ligados a aspectos emocionais e que esta forma de se colocarem tende a ser mais interessante para turistas (MOORE, 2015), os profissionais de turismo devem incentivar o compartilhamento de reações positivas vividas em seu negócio, permitindo influenciar quem busca referências para seu processo decisório. 
Comentários negativos podem impedir a visita e, portanto, impedir que experiências memoráveis e nostálgicas venham à mente.

A demanda crescente por experiências únicas e memoráveis no turismo exige que empresas estejam atentas às preferências dos consumidores por ofertas de produtos e serviços diferenciados (OH ET AL, 2007). Pacotes com descontos para grupos de amigos ou familiares, buscando promover visitas e valorizar a companhia são relevantes. Tratando-se de uma primeira visita ao local de turismo, a sugestão para o profissional de marketing é desenvolver ações positivas inesperadas, que encantem o consumidor e marquem o momento. Sendo expostos a estímulos que promovam recordações positivas do passado, é mais provável que reações afetivas, sentimentos nostálgicos e atitudes favoráveis sejam despertados, levando à decisão de revisita.

Estudos mais aprofundados sobre cada dimensão aqui identificada podem ser realizados futuramente. Entendendo que as companhias de viagem foram importantes para os entrevistados na promoção de experiências memoráveis e nostálgicas, é válido estudar o comportamento, especialmente para viajantes individuais. Em relação a eventos inesperados e momentos não previstos vividos em local de turismo, identificar que surpresas têm mais ligação com experiências memoráveis nostálgicas é uma possibilidade, como também compreender que características principais de sonhos, relacionados a visitas em local de turismo, podem ser relevantes para criar atmosfera favorável e coerente ao desejado.

Levando em consideração que emoções negativas, em determinados contextos, podem incentivar que pessoas identifiquem comportamentos potencialmente prejudiciais em longo prazo (SALERNO ET AL, 2014), é válido estudar os principais obstáculos a experiências positivas no turismo. Situações ruins relacionadas a desconforto, a insegurança, ao clima e a preço ruins foram consideradas negativas pelos entrevistados e podem ser ponto de partida para uma pesquisa futura com foco em compreender aspectos que têm maior potencial de gerar vigilância no comportamento do consumidor e, portanto, afetar negativamente o consumo indulgente. 


\section{Referências bibliográficas}

AHUVIA, A. C. Beyond the Extended Self: Loved Objects and Consumer's Identity Narratives. Journal of Consumer Research, 32 (1), 171-184, 2005.

ARNOLD, M.; REYNOLDS, K. Hedonic shopping motivations. Journal of Retailing, 79 (2), 77-95, 2003.

ASSOCIAÇÃO BRASILEIRA DE EMPRESAS DE EVENTOS. Impacto Econômico de Viagens e Turismo 2014 - WTTC, 2014. Disponível em http://www.abeoc.org.br/2014/05/impacto-economico-de-viagens-eturismo-2014-wttc/. Acesso em 01 de julho de 2016.

BABIN, B.; DARDEN, W.; GRISSIN, M. Work and/or Fun: Measuring Hedonic and Utilitarian Shopping Value. Journal of Consumer Research, 20, 644-656, 1994.

BAKER, S.; KENNEDY, P. Death by nostalgia: A diagnosis of contextspecific cases. Advances in Consumer Research, 21, 169-174, 1994.

BAMBAUER-SACHSE, S.; GIERL, H. Effects of Nostalgic Advertising through Emotions and the Intensity of the Evoked Mental Images. Advances in Consumer Research, 36, 391-398, 2009.

BELK, R. W. Possessions and the Extended Self. Journal of Consumer Research, 15, 139-168, 1988.

. The role of possessions in constructing and maintaining a sense of past. Advances in Consumer Research, 17, 669-676, 1990.

BENAZZI, J. R. Abordagens por Coortes no Brasil e Tendência Nostálgica - Uma Perspectiva de Marketing Aplicada a Atitudes do Consumidor. Dissertação de Mestrado, Pontifícia Universidade Católica do Rio de Janeiro - PUC-Rio, 2000.

BHATTACHARJEE, A.; MOGILNER, C. Happiness from Ordinary and Extraordinary Experiences. Journal of Consumer Research, 41, 1-17, 2014.

BOSANGIT, C.; HIBBERT, S.; MCCABE, S. "If I was going to die I should at least be having fun": Travel blogs, meaning and tourism experience. Annals of Tourism Research, 55, 1-14, 2015.

BROWN, S. The retro-marketing revolution: l'imagination au pouvoir. International Journal of Management Reviews, 3 (4), 303 - 320, 2001. 
BUHALIS, D. Marketing the competitive destination of the future. Tourism Management, 21 (1), 97-116, 2000.

CABIDDU, F.; DE CARLO, M.; PICCOLI, G. Social media affordances: Enabling customer engagement. Annals of Tourism Research, 48, 175192, 2014.

CARÙ, A.; COVA, B. Revisiting Consumption Experience: a more humble but complete view of the concept. Marketing Theory, 3 (2), 267-286, 2003.

CHANDRALAL, L.; VALENZUELA, F. Exploring memorable tourism experiences: antecedents and behavioural outcomes. Journal of Economics and Management, 1 (2), 177-181, 2013.

CHARTRAND, T. L.; HUBER, J.; SHIV, B.; TANNER, R. J. Nonconscious goals and consumer choice. Journal of Consumer Research, 35, 189201, 2008.

CHEN, H.; YEH, S.; HUAN, T. Nostalgic emotion, experiential value, brand image, and consumption intentions of customers of nostalgic-themed restaurants. Journal of Business Research, 67(3), 354-360, 2014.

CLORE, G.; ORTONY, A.; FOSS, M. Foss The Psychological Foundations of the Affective Lexicon. Journal of Personality and Social Psychology, 53 (4), 751-766, 1987.

COHEN, E. A phenomenology of tourist experiences. Sociology, 13, 179201, 1979.

CRESWELL, J. W. Projeto de Pesquisa: Métodos Qualitativo, Quantitativo e Misto. 2a Ed., Porto Alegre: Bookman, 2007.

Qualitative inquiry and research design: Choosing among five traditions. Thousand Oaks, CA: Sage, 1998.

CROMPTON, J. L. Motivations for Pleasure Vacation. Annals of Tourism Research, 6 (4), 408-424, 1979.

CUI, R. A Review of Nostalgic Marketing. Journal of Service Science and Management, 8, 125-131, 2015.

DIJKMANS, C.; KERKNOF, P.; BEUKEBOOM, C. A stage to engage: Social media use and corporate reputation. Tourism Management, 47, 58-67, 2015.

DUNAN, T.; MATTILA, A. S. The role of affective factors on perceived cruise vacation value. Tourism Management, 26, 311-323, 2005.

GORDON, K. Emotion and memory in nostalgia sport tourism: Examining the attraction to postmodern ballparks through an interdisciplinary lens. Journal of Sport \& Tourism, 18 (3), 217-239, 2013. 
GRETZEL; U.; FASENMAIER, D. R.; O'LEARY, J. T. The transformation of consumer behavior. In D. Buhalis; C. Costa (Eds). Tourism Business Frontiers: Consumer, Products and Industry, 9-18. Burlington: MA: Elsevier, 2006.

GROENEWALD, T. A phenomenological research design illustrated. International Journal of Qualitative Methods, 3 (1), 2004.

GUPTA, S.; VAJIC, M. The Contextual and Dialetical Nature of Experiences. New Service Development. USA: Thousand Oaks, CA, SAGE, 1999.

HAVLENA, W. J.; HOLAK, S. L. The Good Old Days: Observations on Nostalgia and Its Role in Consumer Behavior. Advances in Consumer Research, 18, 323-329, 1991.

HIRSCHMAN, E.; HOLBROOK, M. B. Hedonic consumption: emerging concepts, methods and prepositions. Journal of Marketing, 46, 92-101, 1982.

$\mathrm{HOCH}$, S.; DEIGHTON, J. Managing What Consumers Learn from Experience. Journal of Marketing, 53 (April), 1-20, 1989.

HOLAK, S.L.; HAVLENA, W.J.; MATVEEV, A.V. Exploring Nostalgia in Russia: Testing the Index of Nostalgia Proneness. European Advances in Consumer Research, 7, 33-40, 2006.

HOLBROOK, M. B. Nostalgia and Consumption Preferences: Some Emerging Patterns of Consumer Tastes. Journal of Consumer Research, 20(2), 245-256, 1993.

HOLBROOK, M. B.; HIRSCHMAN, E. The experiential aspects of consumption: consumer fantasies, feelings, and fun. Journal of Consumer Research, 9, 132-140, 1982.

HOLBROOK, M. B; SCHINDLER, R. M. Echoes of the Dear Departed Past: Some Work in Progress on Nostalgia. Advances on Consumer Research, 18, 330-333, 1991.

HYCNER, R. Some guidelines for the phenomenological analysis of interview data. Qualitative Research, 3, 143-164, 1999.

IPEA - INSTITUTO DE PESQUISA ECONÔMICA APLICADA. Pesquisa e Planejamento Econômico (PPE), 2010. Disponível em http://ppe.ipea.gov.br/index.php/ppe/issue/view/123. Acesso em 01 de julho de 2016.

JAVIS, D.; STOECKL, N.; LIU, H. The impact of economic, social and environmental factors on trip satisfaction and the likelihood of visitors returning. Tourism Management, 52, 1-18, 2016. 
KAPLAN, A. M.; HAENLEIN, M. Users of the world, unite! The challenges and opportunities of Social Media. Business Horizons, 53 (1), 59-68, 2010.

KIM, J. The antecedents of memorable tourism experiences: the development of a scale to measure the destination attributes associated with memorable experiences. Tourism Management, 44, 34-45, 2014.

KIM, J; RITCHIE, J. R. B.; MCCORMICK; B. Development of a scale to measure memorable tourism experiences. Journal of Travel Research, 51 (1), 12-25, 2012.

LASALETA, J. D.; SEDIKIDES, C.; VOHS, K. D. Nostalgia Weakens the Desire for Money. Journal of Consumer Research, 41 (3), 713-729, 2014.

LEE, Y.. Creating memorable experiences in a reuse heritage site. Annals of Tourism Research, 55, 155-170, 2015.

LEHTO, X.; O'LEARY, J. T.; MORRISON, A. M. The effect of prior experience on vacation behavior. Annals of Tourism Research, 31 (4), 801-818, 2004.

LIU, Z.; PARK, S. What makes a useful online review? Implication for travel product websites. Tourism Management, 47, 140-151, 2015.

LO, I. S.; MCKERCHER, B. Ideal Image in process: Online tourist photography and impression management. Annals of Tourism Research, 52, 104-116, 2015.

MERCHANT, A.; FORD, J. B.; ROSE, G. How personal nostalgia influences giving to charity. Journal of Business Research, 64, 610-616, 2011.

MICHAELIS MODERNO DICIONÁRIO DA LÍNGUA PORTUGUESA 2009. Disponível em <http://michaelis.uol.com.br/moderno/portugues/>. Acesso em 20 outubro 2015.

MOORE, S. G. Attitude Predictability and Helpfulness in Online Reviews: The Role of Explained Actions and Reactions. Journal of Consumer Research, 42, 30-44, 2015.

MUNAR, A. M.; JACOBSEN, J. K. S. Motivations for sharing tourism experiences through social media. Tourism Management, 43, 46-54, 2014.

$\mathrm{OH}, \mathrm{H}$.; FIORE, A. M.; JEOUNG, M. Measuring experience economy concepts: Tourism application. Journal of Travel Research, 46 (2), 119132, 2007. 
PACE, S. YouTube: An opportunity for consumer narrative analysis. Qualitative Market Research: An International Journal, 11(2), 213226, 2008.

PIETERS, R.; RAAIJ, F. V. Functions and Management of Affect: Applications to Economic Behavior. Journal of Economic Psychology, 9, 251-282, 1988.

PINE, J.; GILMORE, J. Welcome to the Experience Economy. Harvard Business Review, July, 1998.

REDER, L.; DONAVOS, D.; ERICKSON, M. Perceptual match effects in direct tests of memory: the role of contextual fan. Memory \& Cognition, 30 (2), 312-323, 2002.

ROUTLEDGE, C.; ARNDT, J.; WILDSCHUT, T.; SEDIKIDES, C.; HART, C. M.; JUHL, J.; VINGERHOETS, J.J.M.; SCHLOTZ, W. The past makes the present meaningful: nostalgia as an existential resource. Journal of Personality and Social Psychology, 101 (3), 638-652, 2011.

RUSSEL, D. Nostalgic Tourism. Journal of Travel \& Tourism Marketing, 25 (2), 103-116, 2008.

SALERNO, A.; LARAN, J.; JANISZEWSKI, C. Hedonic Eating Goals and Emotion: When Sadness Decreases the Desire to Indulge. Journal of Consumer Research, 41, 135-151, 2014.

SEDIKIDES, C.; WILDSCHUT, T.; BADEN, D. Nostalgia: conceptual issues and existencial functions. Handbook of experimental existencial psychology, 200-214. New York: Guilford Press, 2004.

SEEHUSEN, J.; CORDARO, F.; WILDSCHUT, T.; SEDIKIKES, C.; ROUTLEDGE, C.; BLACKHART, G. C.; EPSTUDE, K.; VINGERHOUETS, J.J.M. Individual differences in nostalgia proneness: the integrating role of the need to belong. Personality and Individual Differences, 5, 904-908, 2013.

SENFT, T.; BAYM, N. What does the selfie say? Investigating a Global Phenomenon. International Journal of Communication, 9, 1588-1606, 2015.

SRINIVASAN, S.; SRIVASTANA, R. Creating the futuristic retail experience through experiential marketing: Is it possible? An exploratory study. Journal of Retail \& Leisure Property, 9 (3), 193-199, 2010.

STEPHAN, E.; WILDSCHUT, T.; SEDIKIKES, C.; ZHOU, X.; HE, W.; ROUTLEDGE, C.; CHEUNG, W.; VINGERHOUETS, J.J.M. The Mnemonic mover: nostalgia regulates avoidance and approach motivation. Emotion, 14 (3), 545-561, 2014.

STILLMAN, T. F.; BAUMEISTER, R. F.; LAMBERT, N. M.; CRESCIONI, A. W.; DEWALL, C. N.; FINCHAM, F. D. Alone and without purpose: life 
loses meaning following social exclusion. Journal of Experimental Social Psychology, 45, 686-694, 2009.

THOMPSON; C.; LOCANDER, W.; POLLIO, H. Putting Consumer Experience Back into Consumer Research: The Philosophy and Method of Existential-Phenomenology. Journal of Consumer Research, 16(2), 133146, 1989.

. The lived meaning of free choice: an existential-phenomenological description of everyday consumer experiences of contemporary married women. Journal of Consumer Research, 17 (3), 346-361, 1990.

TUNG, V.; RITCHIE, J. R. B. Exploring the essence of memorable tourism experiences. Annals of Tourism Research, 38 (4), 1367-1386, 2011.

VESS, M.; ARNDT, J.; ROUTLEDGE, C.; SEDIKIDES, C; WILDSCHUT, Tim. Nostalgia as a resource for the self. Self and Identity, 11, 273-284, 2012.

WILDSCHUT, T.; SEDIKIDES, C.; ROUTLEDGE, C.; ARNDT, J.; CORDARO, F. Nostalgia as a Repository of Social Connectedness: The Role of Attachment-Related Avoidance. Journal of Personality and Social Psychology, 98, 573-586, 2010.

WOODSIDE, A.; CALDWELL, M.; ALBERS-MILLER, N. Broadening the study of tourism: Introduction to the special issue on the consumer psychology of travel/tourism behavior. Journal of Travel and Tourism Marketing, 17(1), 1-7, 2004.

WORLD TOURISM ORGANIZATION. Why tourism? Disponível em http://www2.unwto.org. Acesso em 01 de julho de 2016.

YOON, Y.; UYSAL, M. An examination of the effects of motivation and satisfaction on destination loyalty: a structural model. Tourism Management, 26(1), 45-56, 2005.

ZAUBERMAN, G.; RATNER, R. K.; KIM, B. K. Memories as Assets: strategic memory protection in choice over time. Journal of Consumer Research, 35, 715-728, 2008.

ZHOU, X.; WILDSCHUT, T.; SEDIKIDES, C.; SHI, K.; FENG, C. Nostalgia: The gift that keeps on giving. Journal of Consumer Research, 39, 39-50, 2012.

ZIAKAS, V.; BOUKAS, N. Extracting meanings of event tourist experiences: a phenomenological exploration of Limassol Carnival. Journal of Destination Marketing \& Management, 2 (2), 94-107, 2013. 